NBER WORKING PAPER SERIES

\title{
EVIDENCE FROM MATERNITY LEAVE EXPANSIONS OF THE IMPACT OF MATERNAL CARE ON EARLY CHILD DEVELOPMENT
}

\author{
Michael Baker \\ Kevin Milligan \\ Working Paper 13826 \\ http://www.nber.org/papers/w13826 \\ NATIONAL BUREAU OF ECONOMIC RESEARCH \\ 1050 Massachusetts Avenue \\ Cambridge, MA 02138 \\ February 2008
}

We thank Byron Lee and Josh Lewis for excellent research assistance. We received many helpful comments from presentations at the NBER Summer Institute, the AEA meetings, UBC empirical lunch, McMaster University, Rand, and UC Davis. We also gratefully acknowledge the research support of SSHRC (Baker Grant , \#410-2005-0486, Milligan Grant \#410-2002-0299). Finally, we thank the staffs of the Toronto and B.C. Research Data Centres for their technical support. This paper represents the views of the authors and does not necessarily reflect the views of Statistics Canada or the National Bureau of Economic Research.

NBER working papers are circulated for discussion and comment purposes. They have not been peerreviewed or been subject to the review by the NBER Board of Directors that accompanies official NBER publications.

(C) 2008 by Michael Baker and Kevin Milligan. All rights reserved. Short sections of text, not to exceed two paragraphs, may be quoted without explicit permission provided that full credit, including $\odot$ notice, is given to the source. 
Evidence From Maternity Leave Expansions of the Impact of Maternal Care on Early Child

Development

Michael Baker and Kevin Milligan

NBER Working Paper No. 13826

February 2008

JEL No. J13,J22

\begin{abstract}
We study the impact of maternal care on early child development using an expansion in Canadian maternity leave entitlements. Following the leave expansion, mothers who took leave spent between 48 and 58 percent more time not working in the first year of their children's lives. We find that this extra maternal care primarily crowded out home-based care by unlicensed non-relatives, and replaced mostly full-time work. However, the estimates suggest a weak impact of the increase in maternal care on indicators of child development. Measures of family environment and motor-social development showed changes very close to zero. Some improvements in temperament were observed but occurred both for treated and untreated children.
\end{abstract}

\author{
Michael Baker \\ Department of Economics \\ University of Toronto \\ 150 St. George Street \\ Toronto, Ontario M5S 3G7 CANADA \\ and NBER \\ baker@chass.utoronto.ca \\ Kevin Milligan \\ Department of Economics \\ University of British Columbia \\ \#997-1873 East Mall \\ Vancouver, B.C. \\ CANADA V6T1Z1 \\ and NBER \\ kevin.milligan@ubc.ca
}




\subsection{Introduction}

Is parental or non-parental care best for children? Conflicting answers to this question fuel the so-called 'mommy wars' over maternal work when children are young. One source of the lack agreement is that non-parental care appears to have different impacts in different populations. Karoly et al. (1998) summarize the compelling evidence from social experiments showing that high quality early childhood care interventions can improve cognitive outcomes for children at risk. On the other hand, recent evidence from samples including all types of children suggests that non-parental care can lead to behavioral problems and that maternal employment in a child's first year of life can lead to delayed cognitive development.

Commentators have pointed out that the credibility of the inferences in this literature varies considerably owing to differences in empirical design. Perhaps the strongest evidence is for at-risk children, because experimental designs have featured randomization into high quality non-parental care. However, current policy debate centers not on targeted interventions for atrisk children, but on universal programs such as pre-school for 4 year olds, extensions of maternity leave in the US, or universal child care programs for infants in Canada. There is much less experimental evidence for broader populations of children, so inferences lean more heavily on observation: comparisons of children whose parents have chosen non-parental care to children whose parents have not.

In this paper we provide new evidence on the developmental impact of maternal care based in a significant increase in maternity/parental leave in Canada. At the end of 2000, the duration of job-protected, partially-compensated, maternity leave increased from roughly six months to one year in most provinces. Many mothers were thereby provided with an opportunity to significantly extend the period they remained at home post-birth. Importantly, this episode 
allows a researcher to study observationally equivalent women having children in neighboring years under starkly different maternity leave policy regimes. This provides a source of exogenous variation in the exposure to maternal care for a wide spectrum of children.

Our results on child development rest on the strength of this first-stage relationship between maternity leave and time at home. Following Baker and Milligan $(2005,2007)$ and Hanratty and Trzcinski (2006), we show that the increase in maternity leave led to a very substantial increase in the amount of maternal care Canadian children received in the first year of life. For mothers who were eligible for leave, we estimate that the amount of maternal care their children received in the first year of life rose by over 3 months, an increase of roughly 50 percent over the pre-reform average. Importantly, this increase in maternal care led to a large reduction in maternal full-time work. Previous research identifies a negative link between full time maternal work in a child's first year of life and their subsequent cognitive development.

Of course, any effect of an increase in maternal care depends on what type of care is displaced. We find the increase in maternal care is associated with a large decline in unlicensed care provided by a non-relative in someone else's home. Past research has raised questions about the quality of this type of care, so the contrast to maternal care is clear.

To investigate the impact of this significant change in the care of young infants, we draw on the National Longitudinal Survey of Children and Youth (NLSCY). The NLSCY is a nationally representative survey that tracks the behavioral, social, emotional and cognitive development of children. We currently observe children born after the change in maternity leave up to age 29 months. At these ages the NLSCY provides a variety of parent-reported information. These include measures of parenting, temperament, social/motor development, the achievement of milestones, family function and children's social and family environment. While some of these indicators are related to subsequent cognitive performance, we also note that they 
may be important for adult economic success in their own right (Heckman, Stixrud and Urzua 2006).

We find that the reform led to a significant increase in the amount of maternal care children received, with corresponding decreases in full time maternal employment and unlicensed non-relative care in someone else's home. The impact of these changes on our measures of development, however, is negligible. The effects on measures of family environment and motor-social development are very close to zero. Some improvements in temperament are observed but appear to reflect common trends across all mothers rather than only mothers eligible for the leave.

\subsection{Previous research on care at young ages}

For the vast majority of mothers, work and non-parental care go hand in hand when their children are very young. Therefore a focus of the literature is on the relationship between child development and the mother's decision to work when their child is an infant.

The National Longitudinal Study of Youth (NLSY) is a source for much of the research on this topic in the United States. The majority of studies on early maternal employment (specifically, the first year of life) using these data find negative effects on later cognitive outcomes, although there is some dissent (see Waldfogel et al. 2002; Bernal and Keane 2006). This conclusion is supported by analysis of the NICHD-SECC data (Brooks-Gunn et al. 2002), which concludes that full-time maternal employment in the ninth month of life has negative cognitive effects that manifest by 3 years of age. As a point of contrast, studies using various other data generally find no negative impact of early maternal employment on the outcomes of 
school aged children (see Brooks-Gunn et al. 2002). ${ }^{1}$ Nevertheless, in her survey of this literature Waldfogel (2006) concludes that “...the research on this point is now quite clear. Children do fare better on average if their mothers do not work full-time in the first year of life, although... the effects vary by context" (p.45).

Complementary to this research are studies of the effects of non-parental care on other dimensions of development. Magnuson et al. (2007), Baker et al. (2005), Loeb et al. (2007) and the research summarized in Belsky (2006) suggest that larger and longer exposures to nonparental care lead to problem behavior: disobedience, defiance and aggression. The risk appears to grow both in the cumulative duration (months) and intensity (hours per week) of exposure in the first years. Loeb et al. (2007) finds that entry into non-parental care before the age of one can have particularly detrimental effects.

In any discussion of these results an outstanding issue is the quality of non-parental care. Measures of child care quality are evolving, and often expensive to collect. The data that exist suggest that while higher quality child care can enhance the cognitive benefits of non-parental care for older children (Belsky 2006), it does not attenuate any negative effect of early maternal employment (Brooks-Gunn et al. 2002). Furthermore, quality does not appear to play a strong mediating role in the relationship between exposure to non-parental care and behavior (Belsky 2006).

Against this background, our study has a number of attractive features. First, the change in maternal care we observe spans the 9 months-old milestone where previous research has found a relationship between maternal employment and cognitive development. Second, we have access to a relatively rich description of the children's environment. Finally, the variation in

\footnotetext{
${ }^{1}$ These conclusions contrast with studies of the effects of pre-kindergarten that more consistently show positive cognitive effects. See for example, Magnuson et al. (2007).
} 
maternal care we observe as a result of the maternity leave reform is less likely correlated with other determinants of children's outcomes. In many of the previous studies cited, the inference is observational rather than causal, and so may be biased by unobservable background factors that differ systematically across families. Progress in the literature is marked by new data sets (e.g., the NICHD SECC) that gather more extensive menus of observable background factors in the hope that the additional factors can contain any selection effects. In contrast, our study makes use of policy-induced variation in maternal care. While more likely free of omitted variables biases, our inference is limited to mothers whose choice of time at home post-birth responds to changes in maternity mandates and compensation.

\subsection{Maternity Leave Policy}

Jurisdiction over maternity leaves in Canada is split between the federal and provincial governments. Provincial labor standards legislation governs the amount of time that mothers may stay at home post-birth with a right to return to their old job. The legislation typically sets eligibility based on a minimum period of pre-birth employment, bans dismissal due to pregnancy, mandates a maximum duration for leave, mandates a right to return to the previous or a similar job, and specifies which terms of employment are preserved during the leave. In no province is the employer obligated to pay an employee while on this leave.

Income replacement during the leave is funded by the federal government. Within the federal Employment Insurance (EI) system there is a program of maternity/parental (henceforth maternity) leave benefits that mothers may claim when their earnings are interrupted by giving birth. Eligibility and benefit entitlement are determined by the same rules used to calculate unemployment benefits. Benefits are based on earnings averaged over the 6 months preceding the claim. In the period we examine, the replacement rate is $55 \%$ up to a cap of $\$ 39,000$, which 
implies a maximum weekly benefit of $\$ 412.50$ per week. A two week waiting period with zero benefits lowers the effective replacement rate over the full span of the leave. Eligibility is based on a minimum of 600 hours of employment in the 12 months preceding a claim. Claiming these benefits does not trigger any job protection, and some mothers will not return to work after completing a claim.

The reform we analyze originates in the federal EI system. Prior to December 31, 2000, the duration of maternity leave benefits was a maximum of 25 weeks: 15 weeks that could only be claimed by the mother, and a further 10 weeks that could be split by the mother and the father (with no restrictions on how these 10 weeks were split). Starting with children born on December 31, 2000, the total duration of benefits was increased to 50 weeks as the number of weeks of benefits that could be claimed by either the mother or father rose to 35 weeks. The reform also included a reduction of the required hours of employment for eligibility from 700 to 600.

This change in the rules for maternity leave benefits triggered a corresponding change in the duration of job-protected maternity leave in the provinces' labor standards legislation. Prior to December 31, 2000, the duration of the job protection ranged from a low of 18 weeks in Alberta to a high of 70 weeks in Quebec. With the change in the EI rules all provinces except Quebec changed their labor standards legislation to increase the duration of job protection to at least 52 weeks. Most provinces made the change coincident with the change in the EI rules. Alberta (February 7, 2001) and Saskatchewan (June 14, 2001) changed their legislation early in 2001. These changes are summarized in Figure 1.

In addition to any change in maternal care, this reform may also have changed family income because the EI replacement rate is less than 1.0. In some simple simulations, however, we find that on an after-tax/transfer, after childcare cost basis, the effective replacement rate is 
close to 1.0 for a median earning woman. For women earning less than the median, the EI benefit (which depends on previous earnings) is lower but still may yield higher after-tax and after paid childcare income than work. For higher earning women, the effective replacement rate falls beneath 1.0, meaning that they may suffer an income shortfall in the leave extension period relative to the pre-reform situation. We note that these high earnings women are more likely to work for employers that have a program to top up EI benefits to a higher fraction of pre-birth earnings.

\subsection{Data}

Our analysis is based on data from the National Longitudinal Study of Children and Youth (NLSCY). The NLSCY is a nationally representative survey of children that has complete cross-sectional coverage of children aged 0 to 5 over six waves of biannual data starting in 1994-95 and ending in 2004-05. We focus on the children born in years surrounding the reform; in years 1998 through 2003. We can observe these children at ages 6 through 29 months, although certain outcomes are only available for specific age ranges. Below, we describe the measures available to us, and discuss the validity and use of these measures.

The NLSCY includes a wide variety of indicators of child development, home and care environments, school performance and health. At the ages that we observe the treated children both pre cognitive and non cognitive measures are available, but not direct cognitive assessments. $^{2}$

A first set of variables allows us to relate the policy change to the children's care environment. For this purpose, there are variables recording the child's age when the mother

\footnotetext{
${ }^{2}$ The first cognitive testing in the NLSCY is performed at 48 months of age.
} 
returned to work, and some limited characteristics of the employment. There are also detailed questions on the types of non-maternal care a child receives, including hours per week and whether the provider is licensed.

The next set of variables describes the child's development. Many of these variables are available only for particular age ranges. For the ages we study, there are measures of temperament, motor/social development, family function, parenting, parent/child activities and the achievement of milestones. All are parent-reported and obtained through the interview process. Several of these measures have been used in previous research. The Motor and Social Development (MSD) scale (Baker et al. 1993) was developed at the US National Center for Health Statistics for the general measure of early child development in large, population-based surveys. It uses questions with high validity and reliability from leading measures of child development (Denver Prescreening Developmental Questionnaire, Bayley Scales of Infant Development and Gesell Development Schedules). This scale has also been used in the US National Longitudinal Survey of Youth, the British National Child Development Survey, and the US National Health and Nutrition Examination Survey III. The parenting scales, one measuring positive interaction and another measuring practices that provoke aversion, were developed at Chedoke-McMaster Hospital, McMaster University, based in part on the Parent Practices Scale of Strayhorn and Weidman. These scales are also used by the Fast-Track project, an experimental intervention in the US to understand anti-social behavior among young children. The general functioning subscale of the McMaster Family Assessment Device (FAD) is used to measure family (dys)function. The FAD has been used in numerous studies, translated into seven languages and has been extensively evaluated. The NLSCY also includes measures of the ages at which significant milestones are achieved (first steps, first words etc.). The questions about the child's temperament were taken from the Ontario Health Study and the Montreal 
Longitudinal Survey. These questions are based on the Child Behavior Checklist of Achenbach and the Social Behavior Questionnaire. Finally, we also draw on questions about non-school activities of the parent and child and questions about literacy, focusing on how often parents read stories, teach new words and do play activities with their children.

Parent-reported data may suffer from systematic biases. For example, a parent who stays home with a child may have a greater chance of becoming aware of a behavior since more time is spent with the child than if the parent worked. However, reviews of the validity of parentreported data typically suggest they are informative about the underlying object they are intended to measure and often display strong correlation with professional assessment ( De Los Reyes and Kazdin 2005; Rydz et al. 2005). Furthermore, there does not appear to be clear evidence that any bias in parents' reports of their children's development is correlated with their characteristics (De Los Reyes and Kazdin 2005).

\subsection{Empirical Framework and Identification}

In this section we introduce our empirical framework, describe various sample omissions that we make to achieve identification, and discuss some issues of interpretation and estimation.

\subsection{Empirical Framework}

Our inference is based on comparisons of average outcomes by birth cohort. We begin with the estimating equation

$$
y_{i}=X_{i} \beta+\sum_{t} \gamma^{t} Y O B t_{i}+u_{i}
$$


where $y$ is the outcome of interest for individual $i, X$ are conditioning variables and YOB denotes year of birth. ${ }^{3}$ The $\gamma^{t}, t \in\{1999,2000, \ldots, 2003\}$, provide birth cohort-specific estimates of the conditional mean of $y$, relative to the excluded year 1998.

If the reform led causally to a change in a given outcome, we expect that the estimates of $\gamma^{t}$ will display a distinct pattern before and after the program change. The change in maternity leave is in effect for the birth cohorts 2001 through 2003, and so we anticipate a discrete change in the estimates between the cohorts 2000 and 2001. All else equal, we would also expect the estimates for cohorts 1998 through 2000 and for 2001 through 2003 to be relatively similar in the absence of any other factor driving changes in the dependent variable in these years.

A visual inspection of the estimates of $\gamma^{t}$, which we report for each outcome variable in the appendix, provides an informal check of the coherence of the data to the hypothesized pattern. It also allows us to investigate counterfactual policy reforms (for example, supposing the change in maternity leave occurred at the end of 1999 or 2002, instead of at the end of 2000) as a robustness check for our inferences. Once these checks are satisfied, we then summarize the impact of the reform more concisely by estimating the equation

$$
y_{i}=X_{i} \beta+\phi \mathrm{POST}_{i}+\varepsilon_{i}
$$

where POST equals 1 for cohorts born after the reform (2001 or later). POST provides an estimate of the impact of the reform, as the difference in the conditional mean of $y$ between cohorts born before the change in the maternity leave and cohorts born after.

\footnotetext{
${ }^{3}$ The control variables $(X)$ include dummy variables for male children, single month of child's age, province, city size, mothers' and fathers' education (4 categories), age (6 categories) and immigrant status, and the presence of up to 2 older or younger siblings. For some dependent variables we also report a specification that adds the month of birth provincial unemployment rate as a control for local labor market conditions. Because the interview process spans several months, we use the average unemployment rate for the months September through May in the relevant years.
} 


\subsection{Identification and Interpretation}

The success of this strategy, of course, is not assured. Generally, conditional on the Xs the estimate of POST will pick up any unobserved variable that is correlated with it and the dependent variable. For example, underlying trends in the outcome measures or other changes in the developmental environment of the children could contaminate our estimate of POST. We can anticipate some of these unobserved variables and control for them through adjustments to our sample. We have identified two policy changes of importance, either of which could potentially affect family outcomes or child development and therefore damage the credibility of our inferences.

The first is the extension of the subsidized childcare component of Quebec's family policy to 0 and 1 year olds in the fall of 2000 . Under this extension, children of these ages became eligible for heavily subsidized childcare, at $\$ 5$ per day. Baker et al. (2005) report that the introduction of subsidized childcare in Quebec over the period 1997-2000 had a large impact on the functioning of families with young children, and the behavioral development of these children. To avoid confusing any impact of the change in maternity leave with this change in the price of non-parental care, we omit observations from Quebec from our sample.

The second significant change in policy is the increase to the National Child Benefit, a benefit paid to low-income families with some attachment to the labor force. For example, the annual benefit for single child increased from $\$ 605$ in 1998 to $\$ 1293$ in 2002 . Milligan and Stabile (2007) show that this change had a substantial impact on the employment of single mothers. Because the benefit is income-tested at the family level, it had a much smaller effect on two parent families. ${ }^{4}$ As a result, we omit observations for single-parent families from our

\footnotetext{
${ }^{4}$ In 1998, the National Child Benefit was reduced to zero for family incomes above $\$ 25,921$. By 2002, this threshold had reached $\$ 32,960$. A much smaller proportion of two-parent families fall under these thresholds.
} 
analysis sample. It is worth noting that due to relatively low rates of single parenthood in Canada, this omission removes only about 10 percent of births over the period. ${ }^{5}$

An alternative to tailoring the sample to exclude specific confounding factors is to construct a control group of children who are exposed to the same influences as children in our analysis sample, with the exception of the change in maternity leave. While older children might be natural candidates for this role since they appear in the same waves of the survey but were born too early to be affected by the maternity leave change, this idea is frustrated by the structure of the NLSCY. There are distinct differences in the indices of development, family function and the questions about non-school activities for different age groups that render these measures less comparable across ages.

Because we do not observe pre-birth employment consistently across waves in the NLSCY, we cannot precisely identify those women who were eligible either for job-protected leave or for EI maternity benefits. As a result, our analysis samples contain mothers who were potentially ineligible because of insufficient work prior to the child's birth and also those who may have been eligible but did not take benefits to which they were entitled. For this reason, equations (1) or (2) should be interpreted as an "intention to treat" design, with 'eligibility' meaning the mother had a child after December 31, 2000 and 'take-up' meaning that the new mother actually took a leave. ${ }^{6}$

The intention-to-treat estimates are informative about the impact on child development of having a child after the policy changed. This is interesting if one is concerned about the population-level impact of the policy change. More informative about individual behavior is the

\footnotetext{
${ }^{5}$ In addition to the omissions described in the main text, we also exclude the very small number of children born in Alberta and Saskatchewan in the months between December 2000 and the point when the provincial maternity leave mandate changes a few months later.

${ }^{6} \mathrm{In}$ an intention to treat design, assignment to treat is random, but take-up of the intervention among the eligible is less than complete. See Bloom (1984).
} 
'treatment on the treated' parameter, which measures the impact of actually taking a leave on child development. To move from the intention-to-treat to the treatment on the treated parameters requires us to scale the intention to treat estimates by a factor reflecting the proportion of women who had a birth and took a leave. ${ }^{7}$

To implement this scaling, we take the following approach. In Statistics Canada's Survey of Employment Insurance Coverage data, 70 percent of mothers with children aged less than one year had insured employment in the 12 months preceding childbirth in 2000 , rising to between 74 and 75 percent in 2001 through $2005 .^{8}$ If this pre-birth employment meant these mothers were eligible for the job protection aspect of maternity leave, then we should scale our estimates by $1.33(1 / 0.75)$. The presence of insured employment, however, does not guarantee EI benefit receipt. These same data show that the proportion of mothers with any insurable employment who ultimately are eligible for and claim benefits is 80 percent in 2000 and 2001 rising to roughly 85 percent in 2002-2005. If we are interested in the impact of being eligible and taking up EI benefits, then we should scale our estimates by $1.57\left(1 /\left(0.75^{*} 0.85\right)\right)$. In the discussion of results that follows we make reference to both the 1.33 and 1.57 scaling factors as the lower and upper bound implied by the available evidence.

Still another method to obtain the treatment effects is to restrict the analysis sample to only those who might be eligible. While the NLSCY does not collect good information on prebirth employment, the information on post-birth employment is much better. We can use this information to select mothers who are likely to have been eligible for both the EI maternity benefits and the job-protected maternity leave. We implement this approach by selecting

\footnotetext{
${ }^{7}$ See Heckman, Lalonde, and Smith (1999).

${ }^{8}$ The source is Statistics Canada (2006), which reports results from the Survey of Employment Insurance Coverage. The increase between 2000 and 2005 suggests that the reform led to an increase in the pre-birth employment of mothers, but the match is not exact because each survey runs from April though January of the following year. In contrast, the reference period for benefits is for employment in the 12 months preceding the birth of a child who can be up to 12 months old. Unfortunately there are no data on maternity benefits preceding the 2000 survey.
} 
mothers who return to work within a year of their child's birth. Note that a comparison of the results in the restricted and full samples provides yet another check on our identification. The comparison reveals whether "likely eligibles" or "likely ineligibles", as we define them, drive the result in the full sample. This can only be an informal check, however, because the incidence of return to work post-birth is potentially affected by the change in maternity leave.

\subsection{Estimation}

Equations (1) and (2) make clear that an estimate of POST rests on the variation of the conditional mean of $y$ across six birth cohorts. Recently, Donald and Lang (2007) have pointed out the importance of explicitly accounting for the finiteness of the "effective sample" in the estimation - that is, the fact that in some respects we only have six aggregated observations rather than the thousands of individuals in the underlying microdata sample. To account for this, we use a two-step procedure. We first estimate equation (1) with no constant, which provides estimates of the $Y_{\mathrm{O}} \mathrm{B}_{t}$ effects for each birth cohort. ${ }^{9}$ We then use these estimates as the dependent variable in a six observation regression following equation (2), except the only explanatory variables are a constant and POST, and we weight by the sum of the individual weights by year of birth. There are 4 degrees of freedom in these regressions so the critical value for statistical significance at the 5-percent level is 2.78 . All the substantial inferences of the paper are robust to alternative methods of calculating the standard errors. ${ }^{10}$

\footnotetext{
${ }^{9}$ These are similar to the $\gamma^{t}$ reported in the Appendix, but rescaled since we now include the full set of cohort dummies including one for the 1998 birth cohort.

${ }^{10}$ We tried various other methods for calculating standard errors. First we tried using robust standard errors and clustering on the year of birth. The resulting standard errors were implausibly small. Second, we tried a model fully saturated with province-year of birth interactions, then regressed the interaction coefficients on POST. This is similar to the method of Solon, Whatley, and Stevens (1997). Finally, we followed the advice of Bertrand et al. (2004) and regressed our outcomes on a full set of province-POST interactions that then served as the dependent variable for a second stage regression. These last two methods yielded inferences errors to the ones we report.
} 


\subsection{Results}

We present results in three steps. First, we examine the impact of the reforms on work by new mothers - and its complement, maternal time at home. Second we trace the change through to the types and timing of different modes of non-parental care. Finally, we explore the impact of the induced changes in care on child development and the family environment.

\subsection{Maternal care and work}

Estimates of the impact of the increase in maternity leave on the amount of maternal care a child receives are reported in Table 1. As a summary statistic, in the first row we report the result for a measure of the months of maternal care in the child's first year of life. This variable, which takes values between 0 and 12, is constructed from a report of the mother's return to work post-birth. The sample for this analysis is the mothers of children aged 13-29 months, so labor market behavior over the first year of life is fully observable.

The estimate in the first column indicates an increase of 2.2 months, which is 26 percent of the pre-reform mean. The causal interpretation of this estimate is supported by the individual $Y O B$ estimates reported in appendix Table A1. We graph these estimates in Figure 2 to illuminate our identification strategy. There is a clear shift in the estimates starting with the 2001 birth cohort.

This is an intention-to-treat estimate. To obtain the treatment on the treated, we can scale the estimate, resulting in an increase in maternal care of between $(2.2 * 1.333) 2.9$ and $(2.2 * 1.57)$ 3.5 months. The pre-reform mean of this variable among those who actually took maternal leave is presumably different (and likely smaller) than the mean for the full sample. To obtain an estimate of this mean we can restrict the sample to mothers who are likely treated by the policy change based on their post-birth employment behavior. Restricting the sample to mothers who 
returned to work in the 12 months following birth, the estimated increase in maternal care in the first year of life is $3.150(0.239)$ months, which sits at the midpoint of the interval defined by our scaling technique. The pre-reform mean in the sample is 6.02 months indicating that our scaled estimates suggest the reform led to an increase in maternal care of between 48 and 58 percent for treated mothers.

In the third column of Table 1 we add the provincial unemployment rate as an additional regressor. This variable proxies for labor market conditions that could affect the mother's return to work decision. Estimates conditioning on this variable, however, are virtually identical to the originals, suggesting that local labor market conditions were not influencing our results in the second column. We have also estimated a specification (not reported) omitting all the explanatory variables except the $Y O B$ effects. The results are again very similar, revealing that there is no significant observable variation in the types of mothers and families having births as a result of the reform. This provides some additional justification for our empirical approach.

In the next five rows we map out the distribution of the effect across different months over the first year. Recall that before the reform, maternity benefits were available for up to 25 weeks, and job protection was available for 18-35 weeks in the provinces included in the analysis sample. In light of this, the largest impact is exactly where it is expected - in months 6 through 12-and in each case the estimates of the individual $Y O B$ effects (reported in the appendix) support a causal interpretation. The proportional increases are substantial, ranging from 11 percent at 6 months to 67 percent at 12 months. Using the sample of mothers who returned to work in the first year we can obtain (but do not report) direct estimates of these proportional changes for the treated. They range from 17 percent at 6 months through 726 percent at 12 months. 
In the last two rows of Table 1 we investigate the type of work displaced by this increase in time at home. Here, we use the sample of mothers of children aged 7-12 months (the ages that gained leave coverage through the reform), and define $0 / 1$ indicators for currently working and working full time ( $30+$ hours per week). The results indicate a 30 percentage point decrease in the proportion at work, two-thirds of which is a decrease in full-time employment. Therefore, the majority of work displaced by the reform was full-time. This provides important context for our analysis of development, because it is full-time work in this age interval that previous research has related to cognitive delay.

\subsection{Changes in non-parental care}

To interpret our estimates of the impact of the reform on child development, it is useful to know what sort of non-parental care the increase in maternal care displaced. This information is provided in Table 2. We show estimates for two samples: children aged 7-12 months and 13-24 months. We expect the primary impact of the reform to be evident in the younger sample. The older sample provides a check whether there is either a direct impact on older children, or a persistent effect of some impact that starts at a younger age.

In the first row is a global measure of whether the child is in some type of non-parental care. We estimate a decrease of over 18 percentage points for children aged 7-12 months, and effectively no change for children aged 13-24 months. As expected, the primary effect of the reform is at ages 7-12 months. However, the magnitude of the effect presents a puzzle as it does not match the decrease in work of the mothers of these children reported in Table 1. We resolve this discrepancy in the next four rows where we split the sample into four mutually exclusive categories: 1) mothers who work and use (non-parental) care, 2) mothers who work and don't 
use care, 3) mothers who don't work and use care, and 4) mothers who do not work and do not use care. The results reveal that the 29 percentage point decrease in work is split across mothers who do and do not use care $(0.23+0.06)$. The 0.186 decrease in non-parental care reflects the balance of a reduction in work with care $(-0.23)$ and an increase in no work with care $(+0.04)$. As noted by Baker et al. (2005), the non-trivial proportion of mothers reporting work with no care is likely a result of the underreporting of very informal care arrangements in the NLSCY. As a result, the increase in maternal care as a result of the reform likely exceeds the direct estimate of 18 percentage points. Furthermore, scaling for treatment, the impact on those likely eligible for leave is at least 25 to 29 points.

In the next row of the table we report the result for the number of hours per week if in care. In the younger sample there is a significant reduction of over 5 hours off a pre-reform mean of 29 hours. There are at least two explanations of this result. First, there is a composition effect resulting from the fact that the mothers who stay home longer after the reform would otherwise be heavy users of non-parental care. Second, the longer periods at home post-birth after the reform allowed mothers to introduce their children to non-parental care more gradually. While the former explanation is consistent with the strong decrease in full-time work, the latter explanation may be consistent with the increase in the proportion of mothers not at work and using care.

The remaining rows of Table 2 disaggregate the changes in non-parental care. For ages 7-12 months, the drop in care in another's home is 11.7 percentage points, of which 10.0 percentage points is unlicensed. Most of this ( 7.0 percentage points) is in the homes of nonrelatives, while 2.9 percentage points is in the homes of relatives. Again, the estimates of the individual $Y O B$ estimates in the Appendix support a causal interpretation of these changes. A 
basis for expecting a change in child development from the reform depends on the extent that the quality of care between unlicensed non-relatives and mothers differs.

\subsection{Changes in development and environment}

We now turn to our measures of child development and of the domestic environment. Again, we examine children aged 7-12 months and 13-24 months separately, looking for both concurrent and persistent effects of the strong increase in maternal care.

In the first three rows of Table $3 \mathrm{a}$ we present the results for indices of parenting behavior and family function. Each is built up from the answers to a series of questions about how the parents interact with the child and with each other. The positive parenting index ranges from 0 to 20 with higher scores reflecting more positive behavior. The hostile/ineffective index runs from 0 to 8 and here a higher value indicates less effectiveness. Finally, the family functioning scale ranges from 0 to 36 with a higher value indicating more dysfunction. Baker et al. (2005) report a significant deterioration in similar indices as a result of a strong increase in non-parental care following the introduction of heavily subsidized universal childcare in Quebec. In that study, however, the change in care was primarily experienced by children older than the ones studied here.

The estimates for both age groups are mostly small and all are statistically insignificant. Furthermore, in each case the estimates of the individual $Y O B$ effects show regular inter-birth cohort variation that is not related to the timing of the extension of maternity leave. Finally, in many cases the standard errors are small, indicating that our evaluation has some power. Remembering that we need a $t$-value of 2.78 for significance at the 5 percent level, the standard errors for the estimates for positive parenting indicate that we can rule out effects larger than 11 
percent of the standard deviation of the pre-reform mean in the younger sample. For ineffective parenting and family function the corresponding calculations are 15 and 31 percent of the standard deviation. In the older sample they range from 12 to 17 percent. Each of these bounds is fairly small given the large magnitude of the increase in maternal care.

The next set of measures captures different dimensions of the child's temperament. Each is a 7 point scale where lower numbers indicate a better result. For example, a lower value for how easily upset indicates that the child does not get upset very easily. Many of the questions require an evaluation of the child relative to other children, although for some the scale maps out specific responses (for example, how many times per day the child is irritable). We are therefore reluctant to assign a specific interpretation to the magnitude of the estimates, but some meaning can be found in their signs.

Few of the estimates are statistically significant. Furthermore, given the standard errors in most cases we have the power to rule out changes of greater than 10 to 15 percent of a standard deviation. An exception is the estimate for difficulty calming the child, which is positive and statistically significant for both ages and indicates greater difficulty following the maternity leave reform. In each case the individual birth cohort estimates in the appendix suggest a causal effect. For the younger age group this result is accompanied by a statistically significant increase in crying, although in this case the $Y O B$ estimates suggest a causal interpretation is not as clear. We test the robustness of these results below.

In Table 3b, we continue the investigation by looking at security, development, and parental involvement. The first set of variables in the table measure the child's reaction to new experiences, persons and places and may provide some indication of the security they feel. The estimates are negative for persons and places indicating better reactions, and the result for persons is statistically significant in the older sample. The final two variables provide overall 
assessments of the attention the child demands and the level of difficulty they present. The estimates for both variables for both age groups are negative. The estimate for attention in the older sample is statistically significant, and the estimates for difficulty in each sample are just shy of the critical value.

In the next section of Table $3 b$ are the variables for development. First is the estimate for motor/social development. This index is built up from questions about the child's physical (ability to crawl, walk etc.) and cognitive/social (ability to say words, count, wash hands) capabilities. ${ }^{11}$ We use a standardized score that is set to have a population mean of 100 and standard deviation of 15. In application, scores within one standard deviation of the mean are interpreted to be in the range of average development. Baker et al. (2005) found a reduction in this measure of motor/social development with the increase of non-parental care from the Quebec universal childcare program. Here, the point estimates are negative for each age group, but also very small and statistically insignificant. Moreover, the individual YOB estimates in the Appendix provide little evidence of a causal effect. The standard errors imply we have the power to detect impacts of more than 29 (37) percent of a standard deviation of the pre-reform mean in the younger (older) sample.

If we believe the motor/social development measure captures early cognitive skills, then this result suggests that the cognitive effects of early maternal full time employment reported for older children in other studies do not have a manifestation at the younger ages we examine

\footnotetext{
${ }^{11}$ Bodnarchuk and Eaton (2004) find that parent reports of motor and milestone measures perform quite well in their validation exercise.
} 
here. ${ }^{12}$ However, we also note that our result contrasts with some previous observational evidence of the effect of maternal care on motor/social development using NLSCY data. ${ }^{13}$

The next two variables record the age at which certain developmental milestones are attained. We report the results for only two of the five milestones collected in the survey, because changes in the wording of the questions across waves render the interpretation of the others difficult. For both the age at which the child first sat up and the age at which they took their first steps the estimated coefficients are statistically indistinguishable from — and very close to-zero.

The final set of variables in Table $3 \mathrm{~b}$ captures interactions between parents and children that may enhance later cognitive development. Each measure expresses the frequency of the indicated interaction on a five point scale ranging from 1 indicating rarely to 5 indicating daily. In almost all cases the estimates are small and statistically insignificant indicating no change in the frequency of the interaction with the increase in maternal care. The exception is an increase in story telling for the older age group, although interpretation of this result is complicated by the lack of any effect for the younger children. A limitation of these variables is that the highest frequency recorded is daily, so these variables are not able to capture a change in the intensity of a daily interaction.

In general, most results in Tables $3 \mathrm{a}$ and $3 \mathrm{~b}$ show no impact - but there are a few statistically significant effects. However, in an analysis with this many regressions, a certain

\footnotetext{
${ }^{12}$ These effects of full time employment are typically found starting at age 3, although this is in turn the age at which cognitive testing starts to be performed more intensively.

${ }^{13}$ Sherlock et al. (2007) use the same motor/social development scale from the 1998-99 NLSCY wave, comparing the children of mothers who return to work at different times post-birth. They measure impaired development as being more than one standard deviation below the mean and find that each month a mother stays at home post-birth reduces the probability of impaired motor/social development by 3 percent. We tried forming their measure of impairment and applied our estimation methodology to it, finding an estimate on POST of 0.028 (0.020). Moreover, the standard error is small enough to yield sufficient power to detect an effect as small as negative 5.6 percent, which in our sample rules out an impact as large as that found by Sherlock et al. (2007), who found a 3 percent drop for each month of delayed return.
} 
number of statistically significant estimates will be obtained by chance. An examination of the $Y O B$ estimates in the appendix provides a check if these results are causally related to the reform. To provide another perspective, we turn to a control group analysis of the mothers likely not eligible for the extended maternity leave as they show little attachment to the labor force postbirth. Specifically, we compare those who returned to work within twelve months of birth to those who did not; the former sample should have a much higher level of treatment. Recall that we used this strategy for the labor supply results in the discussion of Table 1 and found the estimate from the sample of mothers who returned to work within a year sat amid our estimates of the treatment on the treated by the scaling methods.

The results of this analysis are presented in Table 4 . We expect the estimates from the sample of mothers who returned within a year of birth to be larger than the estimates in Table 3a by a factor of between 1.33 and 1.57 . We expect the estimates for the complementary sample to be close to zero. There is some evidence of this pattern for the calming variable. The estimate in the sample of children whose mother returned to work with in a year is almost statistically significant and just over 20 percent larger than the corresponding estimate in Table 3a. This gives some indication that the calming result is robust. For the attention, new person, difficulty, and stories variables, however, we do not find robustness. The mothers who were likely not eligible show, if anything, a larger effect—although in no cases are the impacts in the two samples statistically distinct. Therefore, this investigation further limits our conclusions, indicating that the increase in time at home had little impact on the development variables in the NLSCY. 


\subsection{Interpretation}

While we have documented very large changes in the maternal care of children aged 7-12 months old, we have found few concurrent or persistent impacts on their development as captured by our NLSCY variables. This may be surprising because previous research suggests non-parental care at these ages can have cognitive effects. Also, the developmental measures in the NLSCY are drawn from best practices in the field and are responsive to changes in nonparental care in other studies. Furthermore, our first stage is very strong: we examine large changes in full-time maternal work and full-time non-parental care which previous studies identify as important.

A priori, the developmental variables we examine provide a reasonable summary of facets of a child's progress that could be affected by a change in care. For example, without committing to the direction of the effect, a child's attainment of certain motor or social milestones or her/his behavioral reaction to changes in places or new persons could depend on whether the majority of his/her care is currently provided by the mother, or in a home-based childcare arrangement. The fact that we do not observe any changes in these outcomes implies one of two possibilities: either the effects are not present, or whatever effects occur they are not captured by the variables available in the NLSCY.

If the effects are not present, some caution in interpretation is still needed. We are only able to observe the children up to age 29 months, so it is possible that in the future some impacts will become evident. That is, the impact may lie dormant and manifest only at older ages. If this occurs, the mechanism for the later impacts will remain unclear since we have not uncovered them here. This would frustrate our understanding of the impact of extra maternal care. We will 
be able to examine this 'dormant impact' hypothesis in the future as later waves of the NLSCY become available.

If instead there are effects on non-parental care at very young ages but the variables in the NLSCY do not capture them, then there are potentially important implications for survey design. While parent-reported measures of development have their critics, they are part of the content of most children's surveys because they are cost effective, can be updated on a regular basis though a remote interview and are generally viewed as being informative about many dimensions of development. If measures of the type available in the NLSCY cannot capture changes that are occurring, then reliance on common parent-reported responses might need review.

A final important issue is the intended purpose of the questions asked about infants. Identifying children who are at risk of developmental delay is one objective. However, a survey that is effective in identifying at-risk children may not be effective in capturing changes in development in the more advantaged population of two-parent families that we study. The tension raised here is the one identified in the introduction: the evaluation of universal public policies may require different evidence than the evidence traditionally used to analyze at-risk families.

\subsection{Conclusions}

The decision of how much and whether to work during the first year of a child's life confronts most new mothers. Research on the developmental costs and benefits of maternal care has produced mixed results - and typically must address the difficult problem of unobserved correlates of the maternal work decision. In this paper, we have presented evidence on the developmental impact of more maternal care resulting from the expansion of maternity leave policies in Canada. Among mothers who took leaves, we estimate an increase in the time at 
home post-birth of around 3 months or over 50 percent of the pre-reform level. This increase in time at home primarily displaced full time work and unlicensed care provided in someone else's home. However, even with these extraordinary changes, we find little evidence of a change in child development. Our estimates indicate that the family atmosphere is unchanged and that temperament and motor-social and developmental milestones respond little to the extra maternal time.

Our study offers three important advantages. First, we address the selection problem generated by unobserved correlates through our exploitation of a policy reform that allows us to view similar families under different policy regimes. Second, the impact of the reform is at ages six to twelve months, a range identified as critical to development is past research. Finally, we study a heterogeneous group of children, which may be more relevant to the evaluation of universal child policies than experimental evidence using only children at risk.

Our primary conclusion that this change in maternal care had little effect on child development up to 2 years of age has two alternative interpretations, which are topics for future research. First, the development impacts of the changes we analyze may manifest at older ages. Second, the parent-reported measures of child development we use, which are common to many surveys, may not capture the changes in development induced by the maternity leave reforms. 


\section{References}

Baker, Michael and Kevin Milligan (2005), "How does job-protected maternity leave affect mothers' employment and infant health?” NBER Working Paper 11135.

Baker, Michael, Jonathan Gruber, and Kevin Milligan (2005), "Universal Childcare, Maternal Labor Supply, and Family Well-being,” NBER Working Paper No. 11832.

Baker, Michael and Kevin Milligan (2007), "Maternal Employment, Breastfeeding, and Health: Evidence from Maternity Leave Mandates” NBER Working Paper No. 13,188.

Baker, P.C., Keck, C.K., Mott, F.L. and Quinlan, S.V., 1993. NLSY child handbook-revised edition: A guide to the 1986-1990 National Longitudinal Survey of Youth child data set, Center for Human Resource Research, The Ohio State University, Columbus, Ohio.

Bates, J.E, Freeland, C.A.B. and M.L. Lounsbury (1979), "Measurement of Infant Difficultness," Child Development, Vol. 50, No. 3, pp. 794-803.

Belsky, J. (2006), "Early child care and early child development: Major findings of the NICHD study of early child care," European Journal of Developmental Psychology, Vol. 3, No. 1, pp. 95-110.

Bernal R, and M Keane (2006), “Child Care Choices and Children's Cognitive Achievement: The Case of Single Mothers," Northwestern University.

Bertrand, Marianne, Esther Duflo, and Sendhil Mullainathan (2004), "How Much Should We Trust Difference in Difference Estimates?" Quarterly Journal of Economics, Vol. 119, No. 1, pp. 249-275.

Bloom, Howard S. (1984), "Accounting for No-Shows in Experimental Evaluation Designs," Evaluation Review, Vol. 8, No. 2, pp. 225-246.

Bodnarchuk, J.L. and W.O. Eaton (2004), “Can Parent Reports be Trusted?” Journal of Applied Developmental Psychology, Vol. 25, No. 4, pp. 481-490.

Brooks-Gunn, Jeanne, Wen-Jui Han, and Jane Waldfogel (2002), "Maternal Employment and Child Cognitive Outcomes in the First Three Years of Life: The NICHD Study of Early Child Care," Child Development, Vol, 73, No. 4, pp. 1052-1072.

Clarke-Stewart, K.A., Fitzpatrick, M.J., Allhusen, V.D. and Goldberg, W.A., (2000), "Measuring difficult temperament the easy way," Journal of Developmental and Behavioral Pediatrics Vol. 21, No. 3, pp. 207-220.

De Los Reyes A. and A.E. Kazdin, "Informant Discrepancies in the Assessment of Childhood Psychopathology: A Critical Review, Theoretical Framework, and Recommendations for Further Study, Psychological Bulletin, 131(4), 2005, 483-509 
Donald, Stephen G. and Kevin Lang (2007), "Inference with Difference in Differences and Other Panel Data," The Review of Economics and Statistics, Vol. 89, No. 2, pp. 221-233.

Hanratty, Maria and Eileen Trzcinski (2006), "Who benefits from expanded paid parental leave? Impact of parental benefit expansions in Canada on mothers' employment after birth," manuscript, University of Minnesota and Wayne State University.

Heckman, James J., Robert J. Lalonde, and Jeffrey A. Smith (1999), "The economics and econometrics of active labor market programs," in Handbook of Labor Economics, Volume 3, Ashley Ashenfelter and David Card (eds.).

Heckman, JamesJ, Jora Stixrud, and Sergio Urzua (2006), “The Effects of cognitive and noncognitive abilities on labor market outcomes and social behavior," NBER Working Paper 12006.

Karoly, Lynn A., Peter W. Greenwood, Susan S. Everingham, Jill Houbé, Rebecca Kilburn, C. Peter Rydell, Matthew Sanders, and James Chiesa (1998), Investing in Our Children: What we know and Don't Know about the Costs and Benefits of Early Childhood Interventions. Santa Moncia, CA: Rand Corporation.

Loeb, Susanna, Margaret Bridges, Daphna Bassok, Bruce Fuller, and Russell W. Rumberger (2007), "How much is too much? The influence of preschool centers on children's social and cognitive development," Economics of Education Review, Vol. 26, No. 1, pp. 52-66.

Magnuson, Katherine A., Christopher Ruhm, and Jane Waldfogel (2007), "Does prekindergarten improve school preparation and performance?" Economics of Education Review, Vol. 26, No. 1, pp. 33-51.

Milligan, Kevin and Mark Stabile (2007), "The integration of child tax credits and welfare: Evidence from the Canadian National Child Benefit program," Journal of Public Economics, Vol. 91, No. 1-2, pp. 305-326.

Rescorla Leslie and Amie Alley (2001), "Validation of the Language Development Survey," Journal of Speech, Language and Hearing Research, Vol. 44, No. 2, pp. 434-445.

Rydz D. Shevell, M.I. Majnemer A. and M Oskou, (2005) "Topical Review: Developmental Screening", Journal of Child Neurology 20 4-21.

Sherlock, R.L., Synnes, A.R., and M. Koehoorn, "Working mothers and early childhood outcomes: Lessons from the Canadian National Longitudinal study on children and youth", Early Human Development (2007), doi:10.1016/j.earlhumdev.2007.06.003

Solon, G., W. Whatley and A.H. Stevens, "Wage changes in intrafirm job mobility over the business cycle: two case studies", Industrial and Labor Relations Review 50 (1997), pp. 402-415 
Spencer N.J. and C. Coe (1996), "The development and validation of a measure of parentreported child health and morbidity: the Warwick Child Health and Morbidity Profile," Child: Care, Health and Development, Vol. 22, No. 6, pp. 367-379.

Statistics Canada 2006: The Daily, November 1, 2006.

http://www.statcan.ca/Daily/English/061101/d061101b.htm

Waldfogel, Jane, What Children Need, Cambridge MA: Harvard University Press, 2006.

Waldfogel, Jane, Wen-Jui Han, and Jeanne Brooks-Gunn (2002), "The Effects of Early Maternal Employment on Child Cognitive Development," Demography, Vol. 39, No. 2, pp. 369-392. 
Figure 1: Job Protected Maternity Leave Mandates by Province

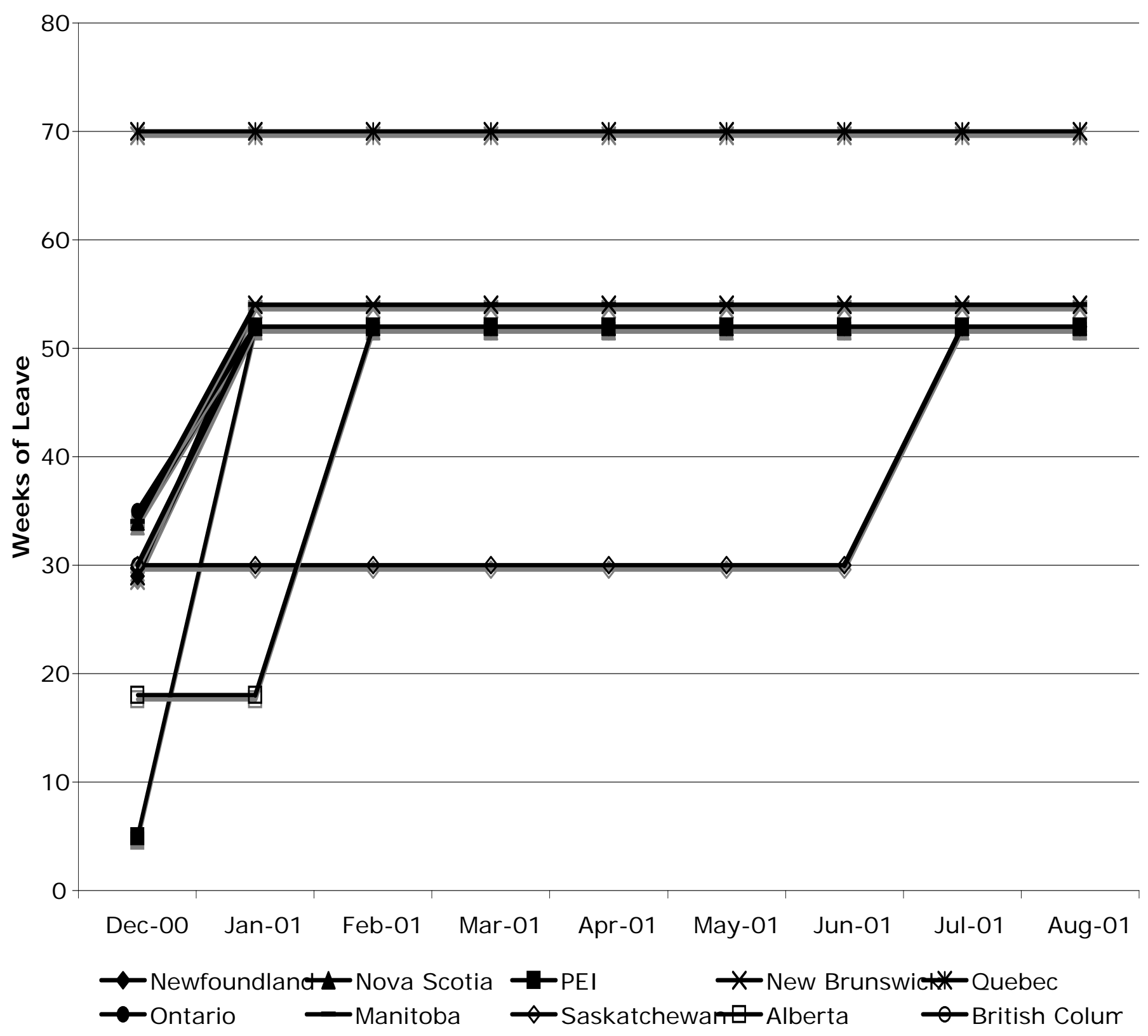

Notes: The lines indicate the number of mandated weeks of job-protected leave by province. 
Figure 2: Months of Maternal Care in First Year Relative to the 1998 Birth Cohort

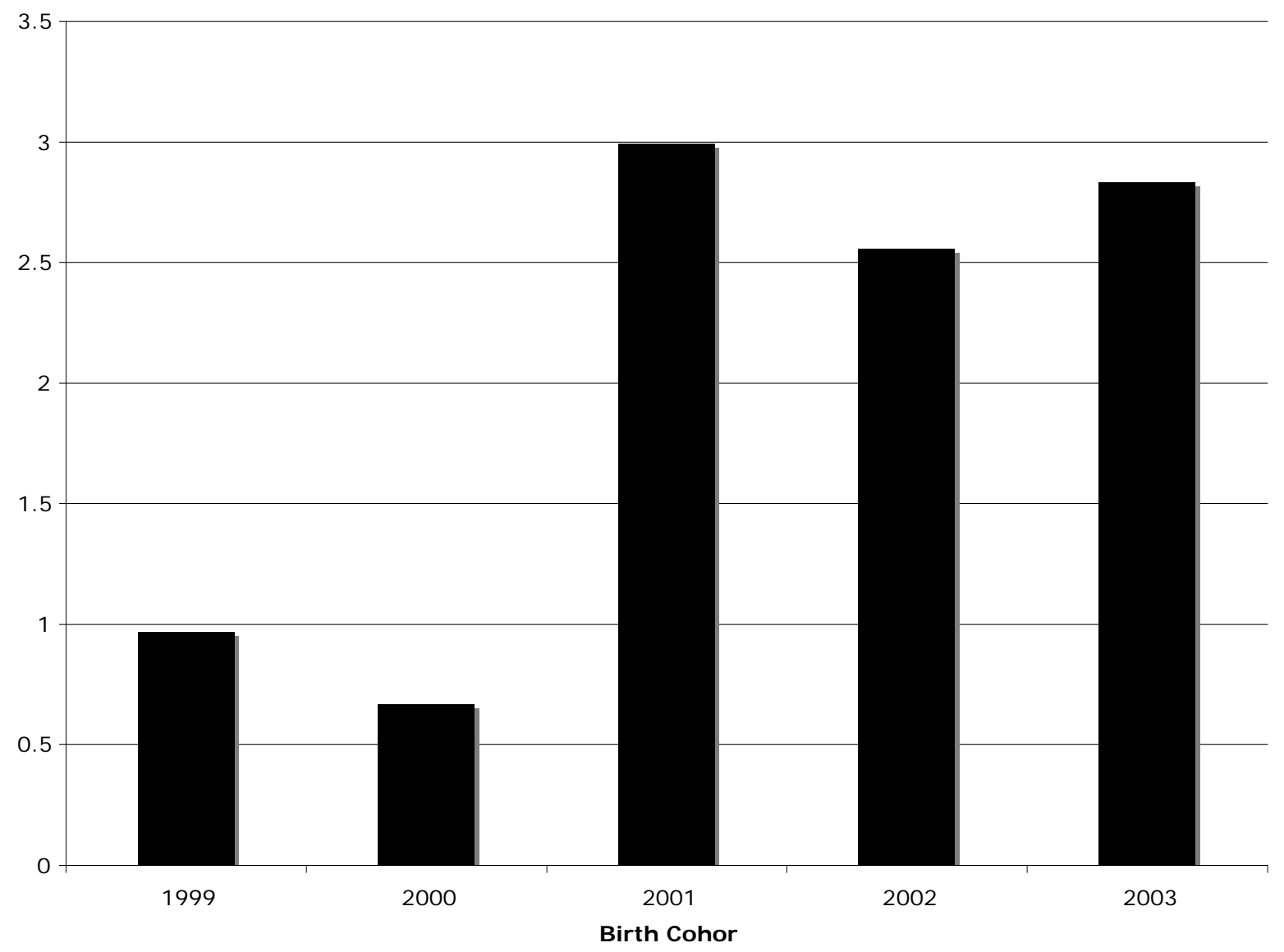

Notes: The bars display the regression coefficients on the $\gamma^{t}$ terms from equation (1) using as a dependent variable the months of maternal care in the first year. The excluded dummy is for $\mathrm{t}=1998$. 
Table 1: Estimated impact of longer maternity leave mandates on time spent at home postbirth

\begin{tabular}{lccc}
\hline & $\begin{array}{c}\text { Pre- } \\
\text { Reform } \\
\text { Mean }\end{array}$ & POST & $\begin{array}{c}\text { POST } \\
\text { with UR } \\
\text { Control }\end{array}$ \\
\hline Months spent at home in first & 8.35 & $2.172^{*}$ & $2.177^{*}$ \\
year & $(3.68)$ & $(0.293)$ & $(0.282)$ \\
Months at home $\geq$ one month & 0.96 & 0.015 & 0.014 \\
& $(0.19)$ & $(0.008)$ & $(0.010)$ \\
Months at home $\geq$ three months & 0.92 & 0.033 & 0.032 \\
& $(0.27)$ & $(0.012)$ & $(0.013)$ \\
Months at home $\geq$ six months & 0.82 & $0.090^{*}$ & $0.091^{*}$ \\
Months at home $\geq$ nine months & $(0.39)$ & $(0.024)$ & $(0.020)$ \\
& 0.49 & $0.354^{*}$ & $0.354^{*}$ \\
Months at home $\geq$ twelve & $(0.50)$ & $(0.039)$ & $(0.038)$ \\
months & 0.42 & $0.280^{*}$ & $0.281^{*}$ \\
Mother Works & $(0.49)$ & $(0.040)$ & $(0.039)$ \\
Mother Works Full-time & & & \\
& 0.55 & $-0.293^{*}$ & $-0.293^{*}$ \\
& $(0.50)$ & $(0.027)$ & $(0.027)$ \\
& 0.34 & $-0.197^{*}$ & $-0.192^{*}$ \\
& $(0.47)$ & $(0.006)$ & $(0.013)$ \\
\hline
\end{tabular}

Notes: $N=6$. A star indicates statistical significance at the $5 \%$ level. The sample for the time at home analysis is the mothers of children aged 13-29 months. The sample for the maternal work analysis is the mothers of children aged 7-12 months. Each row presents analysis of the indicated dependent variable. The first column has the means (standard deviations) of the indicated variable for cohorts born pre-reform. The second column has coefficients (standard errors) for the POST variable described in the text. The third column adds the provincial unemployment rate as a control variable in the second stage. 
Table 2: Estimated impact of longer maternity leave mandates on work and care decisions

\begin{tabular}{|c|c|c|c|c|}
\hline & \multicolumn{2}{|c|}{$\begin{array}{l}\text { Children aged 7-12 } \\
\text { Months }\end{array}$} & \multicolumn{2}{|c|}{$\begin{array}{c}\text { Children aged 13-24 } \\
\text { Months }\end{array}$} \\
\hline & $\begin{array}{l}\text { Pre-Reform } \\
\text { Mean }\end{array}$ & POST & $\begin{array}{c}\text { Pre- } \\
\text { Reform } \\
\text { Mean }\end{array}$ & POST \\
\hline In care & $\begin{array}{c}0.43 \\
(0.49)\end{array}$ & $\begin{array}{l}-0.183 * \\
(0.017)\end{array}$ & $\begin{array}{c}0.47 \\
(0.50)\end{array}$ & $\begin{array}{l}-0.002 \\
(0.008)\end{array}$ \\
\hline Work and care & $\begin{array}{c}0.38 \\
(0.48)\end{array}$ & $\begin{array}{l}-0.228 * \\
(0.005)\end{array}$ & $\begin{array}{c}0.42 \\
(0.49)\end{array}$ & $\begin{array}{l}-0.009 \\
(0.019)\end{array}$ \\
\hline Work and no care & $\begin{array}{c}0.17 \\
(0.38)\end{array}$ & $\begin{array}{l}-0.068 \\
(0.026)\end{array}$ & $\begin{array}{c}0.19 \\
(0.39)\end{array}$ & $\begin{array}{l}-0.007 \\
(0.013)\end{array}$ \\
\hline No work and care & $\begin{array}{c}0.05 \\
(0.22)\end{array}$ & $\begin{array}{c}0.044 \\
(0.020)\end{array}$ & $\begin{array}{c}0.05 \\
(0.21)\end{array}$ & $\begin{array}{c}0.007 \\
(0.014)\end{array}$ \\
\hline No work and no care & $\begin{array}{l}0.40 \\
(0.49)\end{array}$ & $\begin{array}{l}0.251 * \\
(0.019)\end{array}$ & $\begin{array}{c}0.34 \\
(0.47)\end{array}$ & $\begin{array}{c}0.009 \\
(0.020)\end{array}$ \\
\hline Hours of care if in care & $\begin{array}{c}28.9 \\
(16.80)\end{array}$ & $\begin{array}{l}-5.299 * \\
(0.629)\end{array}$ & $\begin{array}{c}29.3 \\
(15.58)\end{array}$ & $\begin{array}{c}0.378 \\
(0.791)\end{array}$ \\
\hline Centre based care & $\begin{array}{c}0.04 \\
(0.19)\end{array}$ & $\begin{array}{l}-0.019 \\
(0.013)\end{array}$ & $\begin{array}{c}0.06 \\
(0.24)\end{array}$ & $\begin{array}{c}0.017 \\
(0.010)\end{array}$ \\
\hline Own home based care & $\begin{array}{c}0.13 \\
(0.33)\end{array}$ & $\begin{array}{l}-0.046^{*} \\
(0.010)\end{array}$ & $\begin{array}{c}0.15 \\
(0.35)\end{array}$ & $\begin{array}{l}-0.030 \\
(0.015)\end{array}$ \\
\hline Other's home based care & $\begin{array}{c}0.26 \\
(0.44)\end{array}$ & $\begin{array}{l}-0.117^{*} \\
(0.009)\end{array}$ & $\begin{array}{c}0.26 \\
(0.44)\end{array}$ & $\begin{array}{c}0.011 \\
(0.017)\end{array}$ \\
\hline $\begin{array}{l}\text { Licensed other's home based } \\
\text { care }\end{array}$ & $\begin{array}{c}0.05 \\
(0.21)\end{array}$ & $\begin{array}{l}-0.017^{*} \\
(0.006)\end{array}$ & $\begin{array}{c}0.04 \\
(0.20)\end{array}$ & $\begin{array}{l}0.040 * \\
(0.005)\end{array}$ \\
\hline $\begin{array}{l}\text { Unlicensed other's home } \\
\text { based care }\end{array}$ & $\begin{array}{c}0.22 \\
(0.41)\end{array}$ & $\begin{array}{l}-0.100 * \\
(0.006)\end{array}$ & $\begin{array}{c}0.22 \\
(0.41)\end{array}$ & $\begin{array}{l}-0.029 \\
(0.015)\end{array}$ \\
\hline $\begin{array}{l}\text { Unlicensed other's home } \\
\text { based care: relative }\end{array}$ & $\begin{array}{c}0.11 \\
(0.31)\end{array}$ & $\begin{array}{l}-0.029 \\
(0.011)\end{array}$ & $\begin{array}{c}0.10 \\
(0.30)\end{array}$ & $\begin{array}{l}-0.002 \\
(0.010)\end{array}$ \\
\hline $\begin{array}{l}\text { Unlicensed other's home } \\
\text { based care: non-relative }\end{array}$ & $\begin{array}{c}0.11 \\
(0.31)\end{array}$ & $\begin{array}{l}-0.070 * \\
(0.012)\end{array}$ & $\begin{array}{c}0.12 \\
(0.32)\end{array}$ & $\begin{array}{l}-0.027 \\
(0.014)\end{array}$ \\
\hline
\end{tabular}

Notes: $\mathrm{N}=6$. A star indicates statistical significance at the 5\% level. Each row presents analysis of the indicated dependent variable. The first two columns show the results for the sample of 712 month olds, and the next two columns for the 13-24 month olds. For each sample we report the means (standard deviations) of the indicated variable for cohorts born pre-reform. We also report the coefficients (standard errors) for the POST variable described in the text. 
Table 3a: Estimated impact of longer maternity leave mandates on parenting and child temperament

\begin{tabular}{lcccc}
\hline & \multicolumn{2}{c}{$7-12$ Months } & \multicolumn{2}{c}{ 13-24 Months } \\
\hline & $\begin{array}{c}\text { Pre-Reform } \\
\text { Mean }\end{array}$ & POST & $\begin{array}{c}\text { Pre-Reform } \\
\text { Mean }\end{array}$ & POST \\
& Parenting & & \\
& & & \\
Positive Parenting & 18.20 & 0.103 & 17.88 & 0.086 \\
& $(1.96)$ & $(0.079)$ & $(2.05)$ & $(0.109)$ \\
Ineffective/Hostile Parenting & 1.47 & 0.129 & 2.68 & 0.066 \\
& $(1.67)$ & $(0.090)$ & $(1.56)$ & $(0.070)$ \\
Family functioning & 8.68 & 0.296 & 9.00 & -0.621 \\
& $(4.92)$ & $(0.552)$ & $(4.81)$ & $(0.298)$ \\
& $C h i l d$ Temperament & & \\
How easily upset & & & & \\
& 2.61 & -0.004 & 3.09 & 0.116 \\
How loud crying when upset & $(1.60)$ & $(0.095)$ & $(1.70)$ & $(0.073)$ \\
& 3.40 & 0.099 & 3.99 & -0.038 \\
How much crying & $(1.85)$ & $(0.056)$ & $(1.90)$ & $(0.051)$ \\
& 1.93 & $0.189^{*}$ & 2.16 & 0.062 \\
Difficulty to calm & $(1.21)$ & $(0.021)$ & $(1.34)$ & $(0.051)$ \\
& 1.79 & $0.268^{*}$ & 2.21 & $0.191^{*}$ \\
How often irritable & $(1.16)$ & $(0.079)$ & $(1.42)$ & $(0.057)$ \\
& 2.31 & 0.090 & 2.38 & 0.061 \\
How much smile/laugh & $(0.85)$ & $(0.038)$ & $(0.98)$ & $(0.046)$ \\
& 1.35 & 0.171 & 1.51 & 0.006 \\
Average mood & $(0.86)$ & $(0.091)$ & $(0.91)$ & $(0.040)$ \\
How changeable is mood & 1.44 & 0.004 & 1.58 & 0.009 \\
& $(1.04)$ & $(0.044)$ & $(0.99)$ & $(0.028)$ \\
& 2.20 & 0.191 & 2.74 & -0.180 \\
& $(1.43)$ & $(0.092)$ & $(1.66)$ & $(0.077)$ \\
\hline
\end{tabular}

Notes: $\mathrm{N}=6$. A star indicates statistical significance at the $5 \%$ level. Each row presents analysis of the indicated dependent variable. The first two columns show the results for the sample of 712 month olds, and the next two columns for the 13-24 month olds. For each sample we report the means (standard deviations) of the indicated variable for cohorts born pre-reform. We also report the coefficients (standard errors) for the POST variable described in the text. 
Table 3b: Estimated impact of longer maternity leave mandates on child security, physical development, and parental involvement

\begin{tabular}{|c|c|c|c|c|}
\hline & \multicolumn{2}{|c|}{ 7-12 Months } & \multicolumn{2}{|c|}{ 13-24 Months } \\
\hline & $\begin{array}{l}\text { Pre-Reform } \\
\text { Mean }\end{array}$ & POST & $\begin{array}{l}\text { Pre-Reform } \\
\text { Mean }\end{array}$ & POST \\
\hline \multicolumn{5}{|c|}{ Child Security } \\
\hline $\begin{array}{l}\text { Response to new things (7-12) } \\
\text { experiences }(13-24)\end{array}$ & $\begin{array}{l}1.70 \\
(1.07)\end{array}$ & $\begin{array}{c}0.101 \\
(0.071)\end{array}$ & $\begin{array}{c}1.91 \\
(1.17)\end{array}$ & $\begin{array}{c}0.106 \\
(0.099)\end{array}$ \\
\hline Response to new person & $\begin{array}{l}2.84 \\
(1.82)\end{array}$ & $\begin{array}{l}-0.170 \\
(0.118)\end{array}$ & $\begin{array}{c}3.29 \\
(1.85)\end{array}$ & $\begin{array}{l}-0.177^{*} \\
(0.060)\end{array}$ \\
\hline Response to new place & $\begin{array}{c}2.19 \\
(1.46)\end{array}$ & $\begin{array}{l}-0.111 \\
(0.115)\end{array}$ & $\begin{array}{c}2.63 \\
(1.60)\end{array}$ & $\begin{array}{l}-0.136 \\
(0.100)\end{array}$ \\
\hline How much attention required & $\begin{array}{c}3.32 \\
(1.73)\end{array}$ & $\begin{array}{l}-0.025 \\
(0.090)\end{array}$ & $\begin{array}{c}3.38 \\
(1.73)\end{array}$ & $\begin{array}{l}-0.112^{*} \\
(0.036)\end{array}$ \\
\hline Overall difficulty of child & $\begin{array}{c}1.99 \\
(1.28)\end{array}$ & $\begin{array}{l}-0.112 \\
(0.043)\end{array}$ & $\begin{array}{c}2.27 \\
(1.33)\end{array}$ & $\begin{array}{l}-0.160 \\
(0.072)\end{array}$ \\
\hline \multicolumn{5}{|c|}{ Development } \\
\hline Motor/social score & $\begin{array}{c}98.81 \\
(15.20)\end{array}$ & $\begin{array}{l}-0.016 \\
(1.609)\end{array}$ & $\begin{array}{l}101.83 \\
(14.73)\end{array}$ & $\begin{array}{l}-0.570 \\
(1.948)\end{array}$ \\
\hline Age at which child sat up & $\begin{array}{c}5.77 \\
(1.44)\end{array}$ & $\begin{array}{l}-0.013 \\
(0.058)\end{array}$ & $\begin{array}{c}5.76 \\
(1.65)\end{array}$ & $\begin{array}{c}0.271 \\
(0.111)\end{array}$ \\
\hline $\begin{array}{l}\text { Age at which child took first } \\
\text { steps }\end{array}$ & $\begin{array}{c}9.46 \\
(1.68)\end{array}$ & $\begin{array}{l}-0.064 \\
(0.085)\end{array}$ & $\begin{array}{l}11.31 \\
(2.09)\end{array}$ & $\begin{array}{l}-0.012 \\
(0.090)\end{array}$ \\
\hline \multicolumn{5}{|c|}{ Parental Involvement } \\
\hline Parent reads to child & $\begin{array}{c}4.30 \\
(1.15)\end{array}$ & $\begin{array}{c}0.066 \\
(0.049)\end{array}$ & $\begin{array}{c}4.68 \\
(0.75)\end{array}$ & $\begin{array}{l}-0.041 \\
(0.034)\end{array}$ \\
\hline Parent teaches new words & $\begin{array}{c}4.25 \\
(1.42)\end{array}$ & $\begin{array}{c}0.126 \\
(0.063)\end{array}$ & $\begin{array}{c}4.77 \\
(0.78)\end{array}$ & $\begin{array}{l}-0.020 \\
(0.043)\end{array}$ \\
\hline Parent tells story & $\begin{array}{c}4.08 \\
(1.40)\end{array}$ & $\begin{array}{c}0.002 \\
(0.070)\end{array}$ & $\begin{array}{c}4.25 \\
(1.28)\end{array}$ & $\begin{array}{l}0.076^{*} \\
(0.019)\end{array}$ \\
\hline Parent plays action games & $\begin{array}{c}4.89 \\
(0.48)\end{array}$ & $\begin{array}{l}-0.045 \\
(0.047)\end{array}$ & $\begin{array}{c}4.79 \\
(0.63)\end{array}$ & $\begin{array}{c}0.025 \\
(0.024)\end{array}$ \\
\hline
\end{tabular}

Notes: $\mathrm{N}=6$. A star indicates statistical significance at the 5\% level. Each row presents analysis of the indicated dependent variable. The first two columns show the results for the sample of 712 month olds, and the next two columns for the 13-24 month olds. For each sample we report the means (standard deviations) of the indicated variable for cohorts born pre-reform. We also report the coefficients (standard errors) for the POST variable described in the text. 
Table 4: Estimated impact of longer maternity leave mandates on measures of temperament behavior in selected samples aged 13-24 months

\begin{tabular}{lcc}
\hline & $\begin{array}{c}\text { Children whose mothers } \\
\text { returned to work within } \\
12 \text { months of birth }\end{array}$ & All other Children \\
\hline Difficulty to calm & 0.230 & 0.108 \\
How much attention required & $(0.091)$ & $(0.083)$ \\
Response to new person & -0.099 & -0.163 \\
Overall difficulty of child & $(0.088)$ & $(0.156)$ \\
& -0.165 & -0.177 \\
Parent tells story & $(0.095)$ & $(0.080)$ \\
& -0.158 & -0.191 \\
& $(0.075)$ & $(0.074)$ \\
& 0.054 & 0.109 \\
\hline
\end{tabular}

Notes: $N=6$. A star indicates statistical significance at the 5\% level. Each row presents analysis of the indicated dependent variable. The first column shows the results for the sample of children with a mother who return to work within 12 months of the birth. The second column shows the results for the sample of all other children. Reported is the coefficient (standard errors) for the POST variable described in the text. 
Table A1: Estimated impact of longer maternity leave mandates on time not at work

\begin{tabular}{lccccc}
\hline & 1999 & 2000 & 2001 & 2002 & 2003 \\
\hline Months not at work in & 0.968 & 0.668 & 2.993 & 2.555 & 2.833 \\
the first year & $(0.220)$ & $(0.227)$ & $(0.217)$ & $(0.216)$ & $(0.220)$ \\
Months not at work $\geq$ & 0.026 & 0.021 & 0.036 & 0.027 & 0.036 \\
one month & $(0.012)$ & $(0.013)$ & $(0.012)$ & $(0.012)$ & $(0.012)$ \\
Months not at work $\geq$ & 0.036 & 0.042 & 0.071 & 0.057 & 0.055 \\
three months & $(0.017)$ & $(0.017)$ & $(0.017)$ & $(0.016)$ & $(0.017)$ \\
Months not at work $\geq$ & 0.068 & 0.058 & 0.160 & 0.111 & 0.139 \\
six months & $(0.023)$ & $(0.024)$ & $(0.023)$ & $(0.023)$ & $(0.023)$ \\
Months not at work $\geq$ & 0.131 & 0.074 & 0.453 & 0.407 & 0.438 \\
nine months & $(0.029)$ & $(0.030)$ & $(0.028)$ & $(0.028)$ & $(0.028)$ \\
Months not at work $\geq$ & 0.127 & 0.056 & 0.373 & 0.318 & 0.360 \\
twelve months & $(0.029)$ & $(0.030)$ & $(0.030)$ & $(0.031)$ & $(0.030)$ \\
Mother Works & -0.069 & -0.045 & -0.384 & -0.302 & -0.358 \\
& $(0.062)$ & $(0.035)$ & $(0.054)$ & $(0.035)$ & $(0.067)$ \\
Mother Works Full- & 0.046 & 0.009 & -0.191 & -0.191 & -0.175 \\
time & $(0.063)$ & $(0.033)$ & $(0.052)$ & $(0.032)$ & $(0.059)$ \\
\hline
\end{tabular}

Notes: $\mathrm{N}=6604$, except 2121 in last two rows. Each row presents analysis of the indicated dependent variable. Reported are the regression coefficients on the $\gamma^{t}$ year effects from equation (1), with $\mathrm{t}=1998$ as the excluded variable. Robust standard errors arein parentheses. 
Table A2: Estimated impact of longer maternity leave mandates on work and care decisions

\begin{tabular}{|c|c|c|c|c|c|}
\hline & 1999 & 2000 & 2001 & 2002 & 2003 \\
\hline \multicolumn{6}{|l|}{ 7-12 months } \\
\hline \multirow[t]{2}{*}{ In care } & 0.036 & 0.041 & -0.144 & -0.164 & -0.168 \\
\hline & $(0.064)$ & $(0.036)$ & $(0.059)$ & $(0.035)$ & $(0.068)$ \\
\hline \multirow[t]{2}{*}{ Work and care } & 0.007 & -0.008 & -0.239 & -0.233 & -0.203 \\
\hline & $(0.063)$ & $(0.033)$ & $(0.052)$ & $(0.032)$ & $(0.062)$ \\
\hline \multirow[t]{2}{*}{ Work and no care } & -0.079 & -0.034 & -0.141 & -0.071 & -0.157 \\
\hline & $(0.046)$ & $(0.027)$ & $(0.029)$ & $(0027)$ & $(0.046)$ \\
\hline \multirow[t]{2}{*}{ No work and care } & 0.029 & 0.049 & 0.095 & 0.069 & 0.035 \\
\hline & $(0.026)$ & $(0.022)$ & $(0.039)$ & $(0.018)$ & $(0.031)$ \\
\hline \multirow[t]{2}{*}{ No work and no care } & 0.043 & -0.006 & 0.285 & 0.235 & 0.325 \\
\hline & $(0.061)$ & $(0.036)$ & $(0.059)$ & $(0.035)$ & $(0.071)$ \\
\hline \multirow[t]{2}{*}{ Centre based care } & 0.016 & 0.032 & 0.012 & -0.005 & -0.012 \\
\hline & $(0.024)$ & $(0.014)$ & $(0.019)$ & $(0.010)$ & $(0.014)$ \\
\hline \multirow[t]{2}{*}{ Own home based care } & 0.024 & 0.005 & -0.003 & -0.042 & -0.096 \\
\hline & $(0.050)$ & $(0.025)$ & $(0.045)$ & $(0.022)$ & $(0.035)$ \\
\hline \multirow[t]{2}{*}{ Other's home based care } & -0.003 & 0.004 & -0.152 & -0.116 & -0.059 \\
\hline & $(0.061)$ & $(0.032)$ & $(0.047)$ & $(0.031)$ & $(0.060)$ \\
\hline \multirow{2}{*}{$\begin{array}{l}\text { Licensed other's home based } \\
\text { care }\end{array}$} & -0.001 & 0.010 & -0.023 & -0.014 & 0.012 \\
\hline & $(0.021)$ & $(0.014)$ & $(0.016)$ & $(0.012)$ & $(0.029)$ \\
\hline \multirow{2}{*}{$\begin{array}{l}\text { Unlicensed other's home } \\
\text { based care }\end{array}$} & -0.002 & -0.006 & -0.130 & -0.101 & -0.071 \\
\hline & $(0.059)$ & $(0.031)$ & $(0.045)$ & $(0.029)$ & $(0.055)$ \\
\hline \multirow{2}{*}{$\begin{array}{l}\text { Unlicensed other's home } \\
\text { based care: relative }\end{array}$} & -0.050 & 0.017 & -0.050 & -0.021 & -0.026 \\
\hline & $(0.035)$ & $(0.026)$ & $(0.034)$ & $(0.026)$ & $(0.044)$ \\
\hline \multirow{2}{*}{$\begin{array}{l}\text { Unlicensed other's home } \\
\text { based care: non-relative }\end{array}$} & 0.048 & -0.023 & -0.080 & -0.081 & -0.045 \\
\hline & $(0.052)$ & $(0.020)$ & $(0.034)$ & $(0.018)$ & $(0.035)$ \\
\hline \multirow[t]{2}{*}{ Hours of care if in care } & 1.830 & 0.230 & -3.720 & -5.586 & -2.864 \\
\hline & $(2.888)$ & $(2.037)$ & $(2.761)$ & $(2.108)$ & (3.364) \\
\hline \multicolumn{6}{|l|}{$13-24$ months } \\
\hline \multirow[t]{2}{*}{ In care } & -0.026 & -0.020 & -0.023 & -0.007 & -0.027 \\
\hline & $(0.037)$ & $(0.038)$ & $(0.037)$ & $(0.038)$ & $(0.038)$ \\
\hline \multirow[t]{2}{*}{ Work and care } & -0.063 & -0.031 & -0.058 & -0.045 & -0.046 \\
\hline & $(0.037)$ & $(0.038)$ & $(0.037)$ & $(0.038)$ & $(0.037)$ \\
\hline \multirow[t]{2}{*}{ Work and no care } & -0.038 & -0.033 & -0.048 & -0.014 & -0.036 \\
\hline & $(0.031)$ & $(0.028)$ & $(0.029)$ & $(0.030)$ & $(0.029)$ \\
\hline \multirow[t]{2}{*}{ No work and care } & 0.038 & 0.011 & 0.036 & 0.039 & 0.018 \\
\hline & $(0.018)$ & $(0.016)$ & $(0.016)$ & $(0.018)$ & $(0.015)$ \\
\hline \multirow[t]{2}{*}{ No work and no care } & 0.064 & 0.053 & 0.071 & 0.020 & 0.063 \\
\hline & $(0.036)$ & $(0.036)$ & $(0.036)$ & $(0.037)$ & $(0.036)$ \\
\hline \multirow[t]{2}{*}{ Centre based care } & 0.017 & 0.028 & 0.023 & 0.029 & 0.048 \\
\hline & $(0.018)$ & $(0.019)$ & $(0.020)$ & $(0.019)$ & $(0.021)$ \\
\hline \multirow[t]{2}{*}{ Own home based care } & 0.000 & -0.045 & -0.036 & -0.041 & -0.050 \\
\hline & $(0.026)$ & $(0.027)$ & $(0.027)$ & $(0.025)$ & $(0.024)$ \\
\hline
\end{tabular}




\begin{tabular}{lccccc} 
Other's home based care & -0.043 & -0.007 & -0.012 & 0.007 & -0.027 \\
& $(0.032)$ & $(0.033)$ & $(0.032)$ & $(0.036)$ & $(0.034)$ \\
Licensed other's home based & -0.006 & 0.010 & 0.037 & 0.037 & 0.044 \\
care & $(0.018)$ & $(0.016)$ & $(0.020)$ & $(0.024)$ & $(0.020)$ \\
Unlicensed other's home & -0.037 & -0.017 & -0.049 & -0.030 & -0.071 \\
based care & $(0.030)$ & $(0.031)$ & $(0.029)$ & $(0.032)$ & $(0.030)$ \\
Unlicensed other's home & -0.009 & 0.023 & -0.000 & -0.000 & -0.001 \\
based care: relative & $(0.022)$ & $(0.025)$ & $(0.021)$ & $(0.024)$ & $(0.023)$ \\
Unlicensed other's home & -0.027 & -0.040 & -0.049 & -0.029 & -0.070 \\
based care: non-relative & $(0.023)$ & $(0.022)$ & $(0.022)$ & $(0.024)$ & $(0.023)$ \\
Hours of care if in care & -1.356 & 0.736 & 0.455 & -0.210 & -0.667 \\
& $(1.654)$ & $(1.619)$ & $(1.537)$ & $(1.874)$ & $(1.692)$ \\
\hline
\end{tabular}

Notes: In the first panel $\mathrm{N}=2121$ for all regressions except the last row where $\mathrm{N}=824$. In the second panel $\mathrm{N}=4469$ for all regressions except the last row where $\mathrm{N}=2283$. Each row presents analysis of the indicated dependent variable. Reported are the regression coefficients on the $\gamma^{\mathrm{t}}$ year effects from equation (1), with $\mathrm{t}=1998$ as the excluded variable. Robust standard errors are in parentheses. 
Table A3: Estimated impact of longer maternity leave mandates on work and care decisions

\begin{tabular}{|c|c|c|c|c|c|c|}
\hline & $\mathrm{N}$ & 1999 & 2000 & 2001 & 2002 & 2003 \\
\hline \multicolumn{7}{|l|}{ 7-12 months } \\
\hline \multirow[t]{2}{*}{ Positive Parenting } & 2078 & 0.005 & 0.122 & 0.347 & 0.178 & -0.254 \\
\hline & & $(0.266)$ & $(0.142)$ & $(0.204)$ & $(0.147)$ & $(0.308)$ \\
\hline \multirow[t]{2}{*}{ Ineffective/Hostile Parenting } & 2102 & -0.105 & 0.112 & 0.518 & 0.119 & 0.117 \\
\hline & & $(0.199)$ & $(0.115)$ & $(0.234)$ & $(0.105)$ & $(0.255)$ \\
\hline \multirow[t]{2}{*}{ Family functioning } & 2063 & 0.364 & 1.329 & 1.391 & 0.958 & 0.046 \\
\hline & & $(0.740)$ & $(0.351)$ & $(0.494)$ & $(0.411)$ & $(0.772)$ \\
\hline \multirow[t]{2}{*}{ How easily upset } & 2113 & 0.012 & 0.188 & -0.098 & 0.131 & -0.053 \\
\hline & & $(0.187)$ & $(0.118)$ & $(0.185)$ & $(0.111)$ & $(0.217)$ \\
\hline \multirow[t]{2}{*}{ How loud crying when upset } & 2112 & -0.067 & 0.004 & 0.358 & 0.086 & -0.184 \\
\hline & & $(0.234)$ & $(0.134)$ & $(0.247)$ & $(0.132)$ & $(0.261)$ \\
\hline \multirow[t]{2}{*}{ How much crying } & 2114 & 0.083 & -0.020 & 0.260 & 0.173 & 0.183 \\
\hline & & $(0.156)$ & $(0.092)$ & $(0.158)$ & $(0.091)$ & $(0.176)$ \\
\hline \multirow[t]{2}{*}{ Difficulty to calm } & 2114 & 0.031 & -0.180 & 0.081 & 0.213 & 0.143 \\
\hline & & $(0.163)$ & $(0.086)$ & $(0.163)$ & $(0.098)$ & $(0.172)$ \\
\hline \multirow[t]{2}{*}{ How often irritable } & 2109 & -0.060 & 0.011 & 0.234 & 0.060 & 0.135 \\
\hline & & $(0.101)$ & $(0.063)$ & $(0.110)$ & $(0.065)$ & $(0.123)$ \\
\hline \multirow[t]{2}{*}{ How much smile/laugh } & 446 & 0.006 & -0.175 & -0.061 & 0.146 & 0.011 \\
\hline & & $(0.227)$ & $(0.164)$ & $(0.206)$ & $(0.242)$ & $(0.239)$ \\
\hline \multirow[t]{2}{*}{ Average Mood } & 1057 & -0.350 & -0.068 & -0.121 & -0.052 & 0.014 \\
\hline & & $(0.149)$ & $(0.173)$ & $(0.138)$ & $(0.131)$ & $(0.182)$ \\
\hline \multirow[t]{2}{*}{ How changeable is mood } & 2108 & 0.056 & -0.124 & -0.089 & 0.205 & -0.067 \\
\hline & & $(0.199)$ & $(0.106)$ & $(0.164)$ & $(0.116)$ & $(0.205)$ \\
\hline \multirow[t]{2}{*}{ Adapts well to bad } & 2110 & -0.034 & -0.166 & -0.080 & 0.041 & 0.017 \\
\hline & & $(0.128)$ & $(0.080)$ & $(0.133)$ & $(0.087)$ & $(0.153)$ \\
\hline \multirow[t]{2}{*}{ Response to new person } & 2111 & 0.213 & 0.135 & -0.164 & -0.010 & -0.643 \\
\hline & & $(0.216)$ & $(0.132)$ & $(0.204)$ & $(0.127)$ & $(0.212)$ \\
\hline \multirow[t]{2}{*}{ Response to new place } & 2105 & -0.054 & -0.260 & -0.170 & -0.205 & -0.542 \\
\hline & & $(0.177)$ & $(0.103)$ & $(0.194)$ & $(0.105)$ & $(0.174)$ \\
\hline \multirow[t]{2}{*}{ How much attention required } & 2109 & -0.294 & -0.168 & 0.101 & -0.117 & -0.466 \\
\hline & & $(0.204)$ & $(0.124)$ & $(0.203)$ & $(0.121)$ & $(0.219)$ \\
\hline \multirow[t]{2}{*}{ Overall difficulty of child } & 2112 & 0.029 & -0.049 & 0.039 & -0.135 & -0.346 \\
\hline & & $(0.155)$ & $(0.097)$ & $(0.166)$ & $(0.091)$ & $(0.163)$ \\
\hline \multirow[t]{2}{*}{ Motor/social score } & 1982 & -4.903 & -3.214 & 1.511 & -2.530 & -0.557 \\
\hline & & $(2.070)$ & $(1.214)$ & $(1.808)$ & $(1.125)$ & $(2.223)$ \\
\hline \multirow[t]{2}{*}{ Age at which child sat up } & 1027 & NA & 0.096 & 0.076 & 0.020 & 0.261 \\
\hline & & & $(0.202)$ & $(0.228)$ & $(0.196)$ & $(0.277)$ \\
\hline \multirow{2}{*}{$\begin{array}{l}\text { Age at which child took first } \\
\text { steps }\end{array}$} & 527 & NA & -0.140 & -0.176 & 0.234 & 0.130 \\
\hline & & & $(0.313)$ & $(0.361)$ & $(0.317)$ & $(0.363)$ \\
\hline \multirow[t]{2}{*}{ Parent reads to child } & 2115 & -0.048 & -0.039 & -0.026 & 0.121 & -0.087 \\
\hline & & $(0.140)$ & $(0.089)$ & $(0.122)$ & $(0.078)$ & $(0.144)$ \\
\hline Parent teaches new words & 1079 & NA & 0.161 & 0.366 & 0.220 & 0.268 \\
\hline
\end{tabular}




\begin{tabular}{|c|c|c|c|c|c|c|}
\hline \multirow{3}{*}{ Parent tells story } & \multirow{3}{*}{1474} & \multirow{3}{*}{ NA } & $(0.177)$ & $(0.192)$ & $(0.169)$ & $(0.237)$ \\
\hline & & & 0.082 & -0.083 & 0.130 & -0.150 \\
\hline & & & $(0.186)$ & $(0.225)$ & $(0.181)$ & $(0.252)$ \\
\hline \multirow[t]{2}{*}{ Parent plays action games } & 1475 & NA & 0.064 & -0.056 & 0.057 & -0.183 \\
\hline & & & $(0.049)$ & $(0.100)$ & $(0.051)$ & $(0.112)$ \\
\hline \multicolumn{7}{|l|}{ 13-24 months } \\
\hline \multirow[t]{2}{*}{ Positive Parenting } & 4303 & 0.246 & 0.118 & 0.361 & 0.267 & 0.110 \\
\hline & & $(0.153)$ & $(0.159)$ & $(0.149)$ & $(0.144)$ & $(0.154)$ \\
\hline \multirow[t]{2}{*}{ Ineffective/Hostile Parenting } & 4300 & -0.019 & -0.070 & -0.066 & 0.200 & 0.047 \\
\hline & & $(0.117)$ & $(0.118)$ & $(0.114)$ & $(0.125)$ & $(0.115)$ \\
\hline \multirow[t]{2}{*}{ Family functioning } & 4298 & 0.153 & 0.981 & -0.055 & -0.317 & -0.474 \\
\hline & & $(0.366)$ & $(0.364)$ & $(0.371)$ & $(0.386)$ & $(0.379)$ \\
\hline \multirow[t]{2}{*}{ How easily upset } & 4441 & -0.021 & 0.210 & 0.157 & 0.206 & 0.143 \\
\hline & & $(0.125)$ & $(0.135)$ & $(0.124)$ & $(0.124)$ & $(0.121)$ \\
\hline \multirow[t]{2}{*}{ How loud crying when upset } & 4443 & 0.083 & 0.117 & 0.065 & 0.120 & -0.041 \\
\hline & & $(0.152)$ & $(0.144)$ & $(0.146)$ & $(0.141)$ & $(0.140)$ \\
\hline \multirow[t]{2}{*}{ How much crying } & 4447 & -0.055 & -0.047 & -0.048 & 0.015 & 0.097 \\
\hline & & $(0.100)$ & $(0.101)$ & $(0.097)$ & $(0.088)$ & $(0.094)$ \\
\hline \multirow[t]{2}{*}{ Difficulty to calm } & 4445 & 0.021 & 0.072 & 0.174 & 0.380 & 0.174 \\
\hline & & $(0.118)$ & $(0.115)$ & $(0.112)$ & $(0.108)$ & $(0.107)$ \\
\hline \multirow[t]{2}{*}{ How often irritable } & 4445 & -0.015 & 0.064 & 0.022 & 0.181 & 0.055 \\
\hline & & $(0.071)$ & $(0.083)$ & $(0.074)$ & $(0.068)$ & $(0.069)$ \\
\hline \multirow[t]{2}{*}{ How much smile/laugh } & 4447 & -0.066 & 0.039 & 0.014 & -0.066 & -0.021 \\
\hline & & $(0.076)$ & $(0.076)$ & $(0.091)$ & $(0.065)$ & $(0.077)$ \\
\hline \multirow[t]{2}{*}{ Average Mood } & 4446 & -0.026 & -0.013 & -0.053 & 0.046 & 0.006 \\
\hline & & $(0.075)$ & $(0.075)$ & $(0.074)$ & $(0.072)$ & $(0.072)$ \\
\hline \multirow[t]{2}{*}{ How changeable is mood } & 4434 & 0.120 & 0.285 & -0.114 & 0.008 & -0.011 \\
\hline & & $(0.121)$ & $(0.130)$ & $(0.111)$ & $(0.111)$ & $(0.116)$ \\
\hline \multirow[t]{2}{*}{ Adapts well to bad } & 4439 & -0.048 & -0.023 & -0.040 & 0.006 & 0.242 \\
\hline & & $(0.088)$ & $(0.102)$ & $(0.086)$ & $(0.090)$ & $(0.088)$ \\
\hline \multirow[t]{2}{*}{ Response to new person } & 4437 & 0.225 & 0.268 & 0.005 & 0.032 & 0.010 \\
\hline & & $(0.135)$ & $(0.141)$ & $(0.133)$ & $(0.121)$ & $(0.132)$ \\
\hline \multirow[t]{2}{*}{ Response to new place } & 4437 & -0.224 & 0.060 & -0.256 & -0.227 & -0.219 \\
\hline & & $(0.116)$ & $(0.128)$ & $(0.112)$ & $(0.113)$ & $(0.114)$ \\
\hline \multirow[t]{2}{*}{ How much attention required } & 4440 & 0.045 & -0.026 & -0.078 & -0.048 & -0.144 \\
\hline & & $(0.130)$ & $(0.135)$ & $(0.125)$ & $(0.128)$ & $(0.125)$ \\
\hline \multirow[t]{2}{*}{ Overall difficulty of child } & 4440 & -0.078 & -0.015 & -0.304 & -0.198 & -0.103 \\
\hline & & $(0.091)$ & $(0.106)$ & $(0.092)$ & $(0.085)$ & $(0.090)$ \\
\hline \multirow[t]{2}{*}{ Motor/social score } & 4326 & 1.867 & -1.354 & 2.490 & -0.246 & -2.408 \\
\hline & & $(1.138)$ & $(1.215)$ & $(1.195)$ & $(1.112)$ & $(1.186)$ \\
\hline \multirow[t]{2}{*}{ Age at which child sat up } & 3432 & NA & -0.067 & 0.093 & 0.271 & 0.496 \\
\hline & & & $(0.140)$ & $(0.111)$ & $(0.148)$ & $(0.118)$ \\
\hline Age at which child took first & 3436 & NA & -0.055 & 0.070 & -0.264 & 0.004 \\
\hline steps & & & $(0.179)$ & $(0.143)$ & $(0.177)$ & $(0.138)$ \\
\hline Parent reads to child & 4457 & 0.119 & 0.123 & 0.039 & 0.101 & 0.043 \\
\hline & & $(0.059)$ & $(0.059)$ & $(0.063)$ & $(0.057)$ & $(0.061)$ \\
\hline
\end{tabular}




\begin{tabular}{lcccccc} 
Parent teaches new words & \multirow{2}{*}{3551} & NA & -0.090 & -0.064 & 0.007 & -0.072 \\
& & & $(0.072)$ & $(0.049)$ & $(0.058)$ & $(0.055)$ \\
Parent tells story & \multirow{2}{*}{3554} & NA & -0.046 & 0.063 & 0.067 & 0.054 \\
& & & $(0.109)$ & $(0.075)$ & $(0.100)$ & $(0.074)$ \\
Parent plays action games & \multirow{2}{*}{3558} & \multirow{2}{*}{ NA } & -0.035 & 0.043 & -0.014 & -0.002 \\
& & & $(0.055)$ & $(0.039)$ & $(0.056)$ & $(0.040)$ \\
\hline
\end{tabular}

Notes: Each row presents analysis of the indicated dependent variable. Reported are the number of observations and regression coefficients on the $\gamma^{\mathrm{t}}$ year effects from equation (1), with $\mathrm{t}=1998$ as the excluded variable. Robust standard errors are in parentheses. NA indicates variable not available for that year. 